\title{
Procyclical Leverage and
}

\section{Value-at-Risk}

Tobias Adrian

Hyun Song Shin

SRC Discussion Paper No 1

September 2013

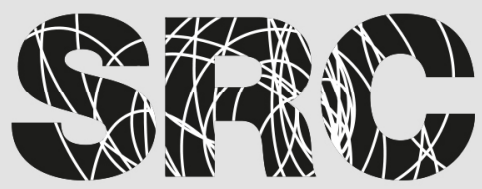

Systemic Risk Centre 


\begin{abstract}
The availability of credit varies over the business cycle through shifts in the leverage of financial intermediaries. Empirically, we find that intermediary leverage is negatively aligned with the banks' value-at-risk ( $\mathrm{VaR})$. Motivated by the evidence, we explore a contracting model that captures the observed features. Under general conditions on the outcome distribution given by Extreme Value Theory (EVT), intermediaries maintain a constant probability of default to shifts in the outcome distribution, implying substantial deleveraging during downturns. For some parameter values, we can solve the model explicitly, thereby endogenizing the VaR threshold probability from the contracting problem.
\end{abstract}

JEL classification: G21, G32

Keywords: financial intermediary leverage, procyclicality, collateralized borrowing

This paper is published as part of the Systemic Risk Centre's Discussion Paper Series. The support of the Economic and Social Research Council (ESRC) in funding the SRC is gratefully acknowledged [grant number ES/K002309/1].

\title{
Acknowledgements
}

The authors are grateful to Viral Acharya, Mark Carey, Helmut Elsinger, Daniel Green, Nobuhiro Kiyotaki, John Moore, Thomas Philippon, Matthew Pritsker, Rafael Repullo, Jean-Charles Rochet, Philipp Schnabl, Martin Summer, Suresh Sundaresan and Pierre-Olivier Weill for comments on earlier drafts. The authors thank the editor, Andrew Karolyi, and two referees for guidance. Evan Friedman provided excellent research assistance. An earlier version of this paper was entitled "Financial Intermediary Leverage and Value-at-Risk". The views expressed in this paper are those of the authors and do not necessarily represent those of the Federal Reserve Bank of New York or the Federal Reserve System.

Tobias Adrian is a Vice President of the Federal Reserve Bank of New York and head of the Capital Markets Function of the Research and Statistics Group. Hyun Song Shin is Hughes-Rogers Professor of Economics at Princeton University.

\section{Published by}

Systemic Risk Centre

The London School of Economics and Political Science

Houghton Street

London WC2A $2 \mathrm{AE}$

All rights reserved. No part of this publication may be reproduced, stored in a retrieval system or transmitted in any form or by any means without the prior permission in writing of the publisher nor be issued to the public or circulated in any form other than that in which it is published.

Requests for permission to reproduce any article or part of the Working Paper should be sent to the editor at the above address.

(C) T Adrian, HS Shin, submitted 2013 


\section{Introduction}

The availability of credit and how credit varies over the business cycle has been a subject of keen interest, especially in the wake of the financial crisis. Some cyclical variation in total lending is to be expected, even in a frictionless world where the conditions of the Modigliani and Miller (1958) theorem hold. There are more positive net present value (NPV) projects that need funding when the economy is strong than when the economy is weak. Therefore, we should expect total credit to increase during the up-swing and decline in the down-swing. The debate about procyclicality of the financial system is therefore more subtle. The question is whether the fluctuations in lending are larger than would be justified by changes in the incidence of positive NPV projects.

We examine the evidence on the procyclicality of lending and explore a possible microfoundation for the observed fluctuations in the availability of credit over the business cycle. Our focus is on the way that credit supply fluctuates as a consequence of how financial intermediaries manage their leverage in reaction to changing economic conditions. Elsewhere (Adrian and Shin (2010)), we documented that the leverage of market-based financial intermediaries was procyclical - that is, leverage is high during booms and low during busts. Procyclicality of leverage is the mirror image of increased collateral requirements (increased "haircuts") during downturns, and Geanakoplos (2009) and Gorton and Metrick (2012) have examined how the risk bearing capacity of the financial system can be severely diminished when leverage falls through an increase in collateral requirements.

Here, we make two contributions. First, we delve deeper into the reasons for the procyclicality of leverage and document the important explanatory role played by measured risks through the firms' disclosed Value-at-Risk. Value-at-Risk (VaR) is a quantile measure on the loss distribution defined as the smallest threshold loss $L$ such that the probability that the realized loss turns out to be larger than $L$ is below some fixed probability $\alpha$. If a bank were to manage its risk by maintaining Value-at-Risk to be no larger 
than its equity capital, the bank would ensure that it remains solvent with probability at least $1-\alpha$. We find that the unit Value-at-Risk, defined as the Value-at-Risk per dollar of assets, fluctuates widely over the financial cycle in step with measures of risk such as the implied volatility of options on the banks' traded shares. However, in contrast to the wide fluctuations in the risk environment through the VaR to asset ratio, there are much more modest fluctuations in the firms' VaR to equity ratio. The difference is accounted for by the active management of leverage by intermediaries, especially the active shedding of risks through deleveraging during times of market stress. Indeed, we show that the evidence is consistent with the rule of thumb that Value-at-Risk normalized by equity is kept constant over the cycle, even at the height of the crisis. The implication is that intermediaries are shedding risks and withdrawing credit precisely when the financial system is under most stress, thereby serving to amplify the downturn.

Our second contribution is theoretical. Based on the evidence, we explore the extent to which a standard contracting model can provide the microfoundations for procyclical leverage driven by Value-at-Risk. In order to keep our framework as close as possible to the existing corporate finance literature, we explore perhaps the simplest possible contracting model where a bank seeks funding from its creditors which it can channel to its customers.

We find that under fairly general conditions on the outcome distribution given by Extreme Value Theory (EVT), a standard contracting framework with risk-shifting moral hazard can generate an exact Value-at-Risk rule, where financial intermediaries keep their book equity matched with their Value-at-Risk at some given confidence level. For some cases, we can solve explicitly for the failure probability $\alpha$ in the VaR rule. In this way, we are able to endogenize the threshold probability $\alpha$ used in the Value-at-Risk rule. The statistical foundations underlying EVT provide some reassurance that our results are applicable to a broad class of problems involving extreme outcomes. Given how widely 
Value-at-Risk is used by financial intermediaries, our framework can thereby provide a bridge between theory and practice.

The implication of our theoretical finding is that the contracting frictions for financial intermediaries can inject considerable procyclicality into the financial system. The outcome of our contracting problem has the creditors imposing a leverage limit on the bank that implies a fixed probability of failure of the bank, irrespective of the risk environment. Since measured risk fluctuates over the cycle, imposing a constant probability of failure implies very substantial expansions and contractions of the balance sheet of the bank for any given level of bank equity. In other words, the contract implies substantial leveraging and deleveraging over the cycle.

Our findings are significant not only for the microfoundations of Value-at-Risk, but also for the contrast with the implications from models that build on standard portfolio choice. For instance, log preferences, which are widely used for their tractability in models of financial intermediation and in applications in macroeconomics have the implication that portfolio leverage increases during busts as investors are attracted by the high risk premium that is available (see Adrian, Colla and Shin (2012)). Relatedly, we also discuss the distinction between leverage inherent in the portfolio of the bank (its book leverage) from the market capitalization and enterprise value of the bank, which focuses on how much the bank is worth to its claim holders. Our concern is with the lending behavior of the bank and so our focus is on the total assets of the bank and its book leverage.

In a concluding section, we discuss the points of contact with the literature and highlight the common threads, including the implications of our results for financial stability analysis and for macro applications. We begin in the next section by reviewing the evidence on the role of Value-at-Risk as a driver in procyclical leverage of financial intermediaries. We then explore the contracting environment and show the key comparative statics result that leverage fluctuates in response to shifts in underlying risk. 
Mode 1: Increased leverage due to equity buyback

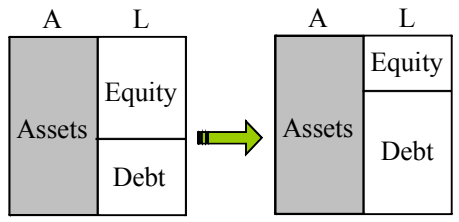

Mode 2: Increased leverage due to fall in asset value

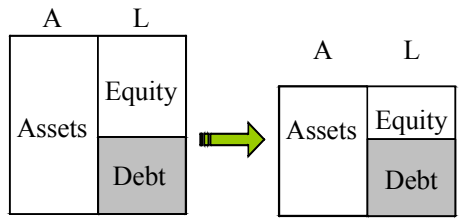

Mode 3: Increase borrowing to fund asset growth

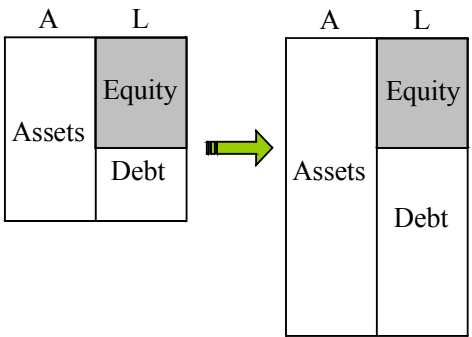

Figure 1: Three modes of leveraging up. Mode 1 is through an equity buyback through a debt issue. Mode 2 is through a dividend financed by asset sale. Mode 3 is through increased borrowing to fund new assets. In each case the grey area indicates balance sheet component that is held fixed

\section{Value-at-Risk and Leverage}

In textbook discussions of corporate financing decisions, the set of positive net present value (NPV) projects is often taken as being given, with the implication that the size of the balance sheet is fixed. Instead, attention falls on how those assets are financed. Leverage then increases by substituting equity for debt, such as through an equity buyback financed by a debt issue, as depicted by the left hand panel in Figure 1.

Figure 1 shows two other modes of leveraging up. In each case, the grey shaded area indicates the balance sheet component that remains fixed. The middle panel depicts the outcome of a dividend payment funded by the sale of assets, with debt held fixed. The middle panel is also closest to the way that leverage fluctuates in Merton's (1974) model of long term debt where leverage fluctuates due to changes in the value of assets, with notional debt held fixed.

However, the first two panels in Figure 1 turns out not to be a good description of the way that banking sector leverage varies over the financial cycle. For US investment banks, Adrian and Shin (2010) show that leverage fluctuates through changes in the total size of the balance sheet, with equity being the exogenous variable. Hence, leverage and total assets tend to move in lock-step, as in the right hand panel of Figure 1.

Figure 2 is the scatter plot of the quarterly change in total assets of the US broker 


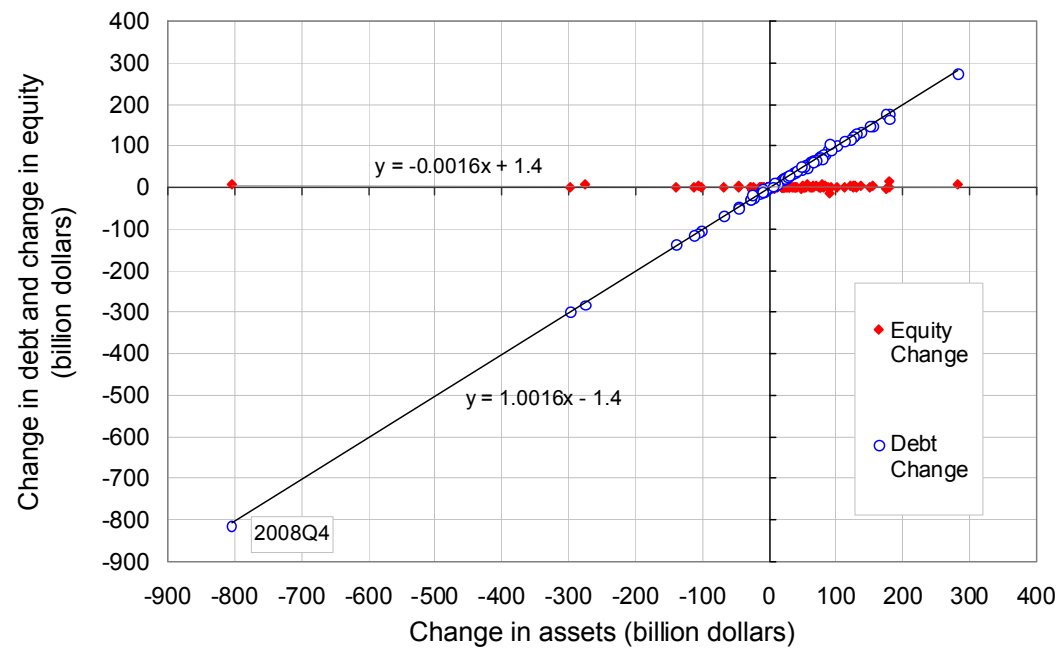

Figure 2: Scatter chart of changes in debt and equity to changes in assets of the US broker dealer sector (1990Q1 - 2012Q2) (Source: Federal Reserve Flow of Funds)

dealer sector where we plot the changes in assets against equity, as well as changes in assets against debt. ${ }^{1}$ More precisely, it plots $\left\{\left(\Delta A_{t}, \Delta E_{t}\right)\right\}$ and $\left\{\left(\Delta A_{t}, \Delta D_{t}\right)\right\}$ where $\Delta A_{t}$ is the change in total assets to quarter $t$, and $\Delta E_{t}$ and $\Delta D_{t}$ are the corresponding changes in equity and debt, respectively. We see from Figure 2 that US broker dealers conform to the right hand panel (mode 3) of Figure 1 in the way that they manage their balance sheets. The fitted line through $\left\{\left(\Delta A_{t}, \Delta D_{t}\right)\right\}$ has slope very close to 1 , meaning that the change in assets in any one quarter is almost all accounted for by the change in debt. The slope of the fitted line through the points $\left\{\left(\Delta A_{t}, \Delta E_{t}\right)\right\}$ is close to zero, indicating that equity is "sticky".

\subsection{Assets versus Enterprise Value}

The equity series in the scatter chart in Figure 2 is of book equity, giving us the difference between the value of the bank's portfolio of claims and its liabilities. An alternative measure of equity would have been the bank's market capitalization, which gives the market price of its traded shares. Note that market capitalization is not the same as

\footnotetext{
${ }^{1}$ The slopes of the two fitted lines sum to 1 due to the additivity of covariances in the regression coefficients and the balance sheet identity $A=D+E$.
} 
the marked-to-market value of the book equity. For securities firms that hold primarily marketable securities and that are financed via repurchase agreements, the book equity of the firm reflects the haircut on the repos, and is fully marked to market.

Market capitalization is the discounted value of the future free cash flows of the securities firm, and will depend on cash flows such as fee income that do not depend directly on the portfolio held by the bank. Focus on market capitalization leads naturally to the consideration of the enterprise value of the bank, which is defined as

$$
\text { Enterprise value }=\text { market capitalization }+ \text { debt }
$$

In this sense, enterprise value is the analogue of the total assets of the bank when market capitalization is considered as a liability. Enterprise value is about how much the bank is worth to its claim holders. For investment decisions, corporate takeovers, or the sale of new ownership stakes, enterprise value is the appropriate value concept.

However, our concern is with the availability of credit through the intermediary, and hence with the lending decisions of the bank. Thus, the appropriate balance sheet concept is that of total assets, rather than enterprise value, since total assets address the issue of how much the bank lends. The corresponding equity concept is book equity, and the appropriate concept of leverage is the ratio of total assets to book equity. Ideally, the book value of equity should be marked-to-market, so that market values are used. ${ }^{2}$ The haircut in a collateralized borrowing arrangement is the best example of book equity that is fully marked-to-market. But we should remember there may only be a loose relationship between the market capitalization of a firm and the marked-to-market value of the firm's book equity, as evidenced by the strong variation of market to book values over time even for intermediaries that hold marketable securities. The loose relationship

\footnotetext{
${ }^{2}$ When assets are illiquid, accounting values may not fully reflect market prices. Bischof, Brüggemann and Daske (2011) discuss one example of illiquid assets giving rise to "stale" book values when fair value reporting requirements were suspended temporariliy at the height of the crisis.
} 
is due to the fact explained above that market equity includes the present value of future cash flows not directly related to the financial assets.

Figure 3 presents side by side the scatter charts for the growth of total assets and enterprise value for the eight largest banks and broker dealers in the US. The group of eight firms includes the (formerly) five largest investment banks (Goldman Sachs, Morgan Stanley, Lehman Brothers, Merrill Lynch, and Bear Stearns) and the three commercial banks with the largest trading operations (JP Morgan Chase, Citibank, and Bank of America). All eight of these institutions have been primary dealers of the Federal Reserve. ${ }^{3}$ Although the three commercial banks have assets that are not marked to market (such as loans), they also have substantial holdings of marketable securities. ${ }^{4}$ The three commercial bank have absorbed some of the largest formerly independent investment banks (Citibank acquired Salomon Brothers in 1998, Chase acquired JP Morgan in 2000 and Bear Stearns in 2008, and Bank of America acquired Merrill Lynch in 2008), and their book equity reflects valuation changes, albeit imperfectly. Institutions that we do not consider in the analysis are the foreign banks, some of which also own substantial trading operations in the US.

The left hand panel of Figure 3 is the scatter chart for the relationship between the asset-weighted growth (quarterly log difference) in book leverage against the assetweighted growth in total assets. The right hand panel of Figure 3 is the corresponding scatter chart where we use enterprise value instead of total assets and use market capitalization instead of book equity.

The left hand panel shows the upward-sloping scatter chart associated with procyclical book leverage as discussed in Adrian and Shin (2010). In contrast, the right hand panel of Figure 3 shows that when leverage is defined as the ratio of enterprise value to market

\footnotetext{
${ }^{3}$ see http://www.newyorkfed.org/markets/pridealers_current.html

${ }^{4}$ Ball, Jayaraman and Shivakumar (2012) report the findings of a detailed investigation of the securities holdings of commercial banks, and find that banks with larger holding of trading securities are associated with share prices with larger bid-ask spreads.
} 

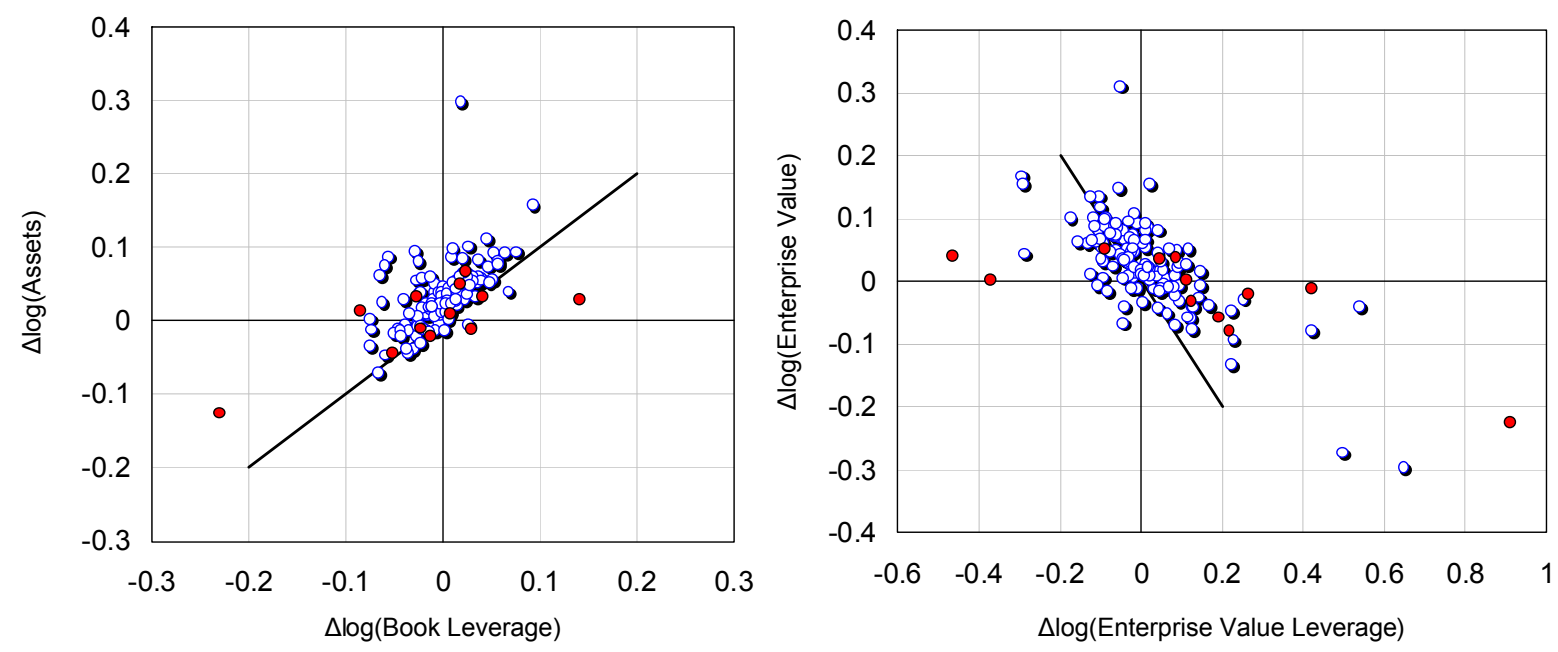

Figure 3: The left panel shows the scatter chart of the asset-weighted growth in book leverage and total assets for the eight largest US broker dealers and banks. The right panel is the scatter for the asset-weighted growth in enterprise value leverage and enterprise value. Enterprise value is the sum of market capitalization and debt, and enterprise value leverage is the ratio of enterprise value to market capitalization. The dark dots are for 2007 - 2009. The eight instutions are Bank of America, Citibank, JP Morgan, Bear Stearns, Goldman Sachs, Lehman Brothers, Merrill Lynch and Morgan Stanley (Source: SEC 10Q filings).

cap, the scatter chart is negatively sloped, so that leverage is high when enterprise value is low. In other words, enterprise value leverage is countercyclical. The interpretation is that during downturns when the value of the bank is low, a greater proportion of the bank's value is held by the creditors, rather than the equity holders. The procyclical and countercyclical leverage plots of Figure 3 are consistent with the finding of Ang, Gorovyy and van Inwegen (2011), who document the countercyclical nature of hedge fund leverage when leverage is computed using market values, consistent with the right plot of Figure 3

Which of the two notion of leverage is relevant depends on the context and the question being addressed. Enterprise value has to do with how much the bank is worth. Assets have to do with how much the bank lends. Regulators and policy makers whose primary concern is with the availability of credit will give weight to the book values for this reason. In our paper, the focus is on the lending decision by banks. Hence, our focus will also be on the total assets of the bank and its book leverage. From now on, when we refer to 
"leverage", we mean book leverage, defined as the ratio to total assets to book equity.

\subsection{Determinants of Leverage}

Our modeling approach is motivated by the patterns observed in Figure 2, and we are interested in the determinants of the bank's leverage. For intermediaries that hold traded securities, we are asking what determines the haircut on the firm's collateralized borrowing. We investigate how the notion of Value-at-Risk can help to explain banks' behavior.

For a bank whose assets today are $A_{0}$, suppose that its total assets next period is given by a random variable $A$. Then, its Value-at-Risk (VaR) represents the "approximate worse case loss" in the sense that the probability that the loss is larger than this approximate worst case loss is less than some small, pre-determined level. Formally, the bank's Value-at-Risk at confidence level $c$ relative to some base level $A_{0}$ is smallest non-negative number $V$ such that

$$
\operatorname{Prob}\left(A<A_{0}-V\right) \leq 1-c
$$

Banks and other financial firms report their Value-at-Risk numbers routinely as part of their financial reporting in their annual reports and as part of their regulatory disclosures. In particular, disclosures on the $10 \mathrm{~K}$ and $10 \mathrm{Q}$ regulatory filings to the US Securities and Exchange Commission (SEC) are available in electronic format from Bloomberg, and we begin with some initial exploration of the data. We begin by summarizing some salient features of the VaR disclosed by the major commercial and investment banks. ${ }^{5}$

Figure 4 plots the asset-weighted average of the $99 \%$ VaR of the eight institutions, obtained from Bloomberg. ${ }^{6} \quad$ The VaRs are reported at either the $95 \%$ or $99 \%$ level, depending on the firm. For those firms for which the $95 \%$ confidence level is reported, we scale the VaR to the $99 \%$ level using the Gaussian assumption. We superimpose on

\footnotetext{
${ }^{5}$ Bank of America, Citibank, JP Morgan, Bear Stearns, Goldman Sachs, Lehman Brothers, Merrill Lynch and Morgan Stanley.

${ }^{6}$ The Bloomberg code is ARDR_TOTAL_VALUE_AT_RISK.
} 


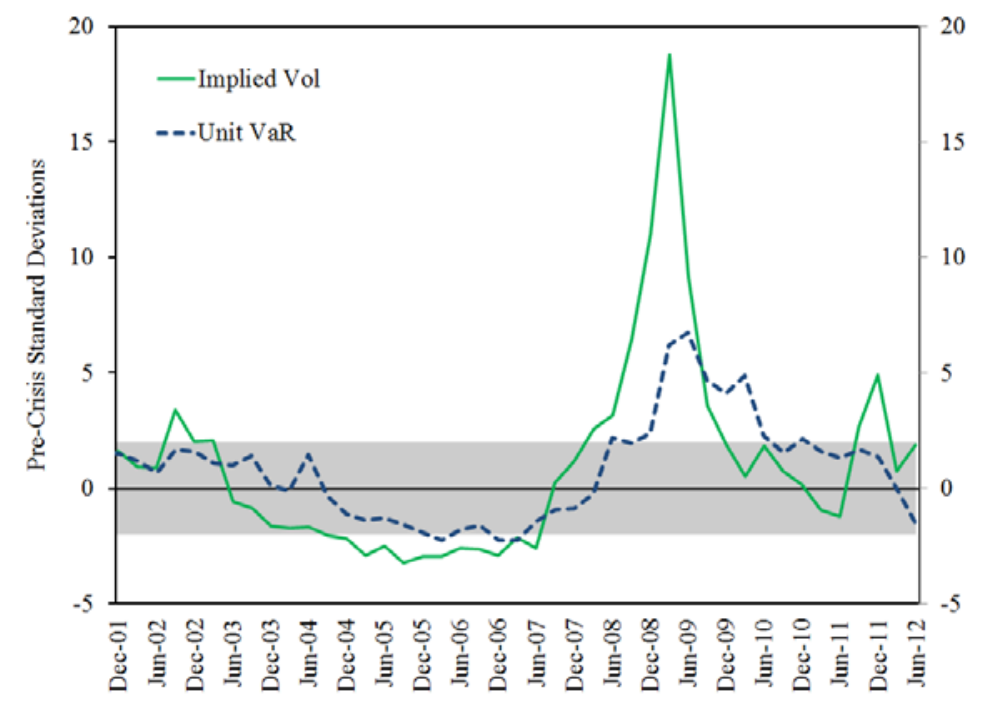

Figure 4: Risk Measures. The figure plots the unit VaR and the implied volatility for the eight large commercial and investment banks. Both variables are standardized relative to the pre-crisis mean and standard deviation. The measures are the lagged weighted averages of the standardized variables across the eight banks, where the weights are lagged total assets. Unit VaR is the ratio of total VaR to total assets. Implied volatilities are from Bloomberg. The grey shaded area indicates \pm 2 standard deviations around zero.

the chart the unit VaR (defined as the VaR per dollar of assets) and the equity implied volatility. Both are measures of firm risk. While the unit VaR is the firms' own assessment of risk, the implied volatility is the market's assesement of equity risk. The vertical scaling is in units of the pre-2007 standard deviations, expressed as deviations from the pre-2007 mean.

Figure 4 shows how the unit VaR compares to the implied volatility of the equity option prices as an alternative risk measure. Between 2001 and the beginning of 2007, the risk measures were stable and moved within a tight band around their mean. However, with the onset of the crisis, both measures spiked. The unit VaR increased over five standard deviations relative to their pre crisis levels. The run-up in implied volatility was even more dramatic at nearly twenty standard deviations relative to the pre crisis level. These series reflect the general mayhem in the markets at the time of the crisis. For our exercise, we can interpret the unit VaR series as reflecting the risk environment of the recent past 


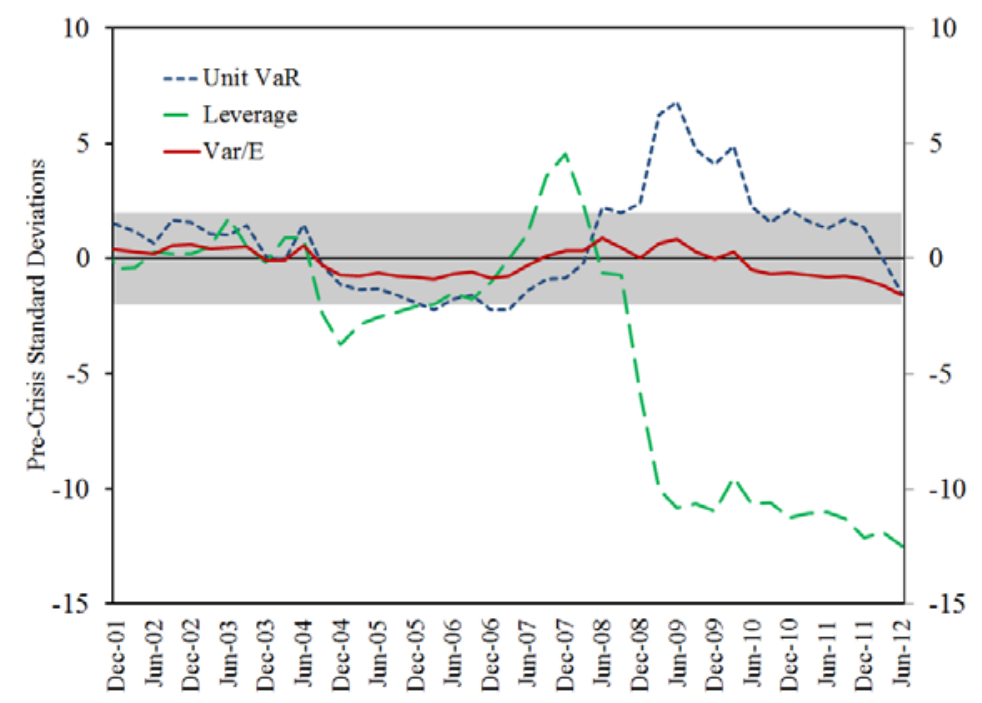

Figure 5: Risk and Balance Sheet Adjustment. This figure plots the unit VaR together with the intermediary balance sheet adjustment variables VaR/Equity and Leverage. All variables are standardized relative to the pre-crisis mean and standard deviation. The measures are the value weighted averages of the standardized variables across the eight banks, where the weights are lagged total assets. Unit VaR is the ratio of total VaR to total assets. VaR/Equity is the ratio of total VaR to total book equity. Leverage is the ratio of total assets to total book equity. The grey shaded area indicates \pm 2 standard deviations around zero.

which the firms take into account when they make decisions on how much risk exposure to take on. Notice the time lag (at around six months) in the spiking of the Unit VaR series relative to the implied volatility series. Whereas the implied volatility series spike in December 2008, the Unit VaR series peaks in June 2009. The lag can be attributed to the backward-looking nature of the VaR estimates, which are based on a window of past data.

Value-at-Risk turns out to be informative in explaining the way that firms manage their balance sheets. Consider the so-called Value-at-Risk (VaR) rule, which stipulates that the financial intermediary maintains enough equity $E$ to cover its Value-at-Risk. The VaR rule can be stated equivalently as maintaining enough equity $E$ so that the bank's probability of failure is kept constant, set to the confidence threshold associated with the 
VaR measure used by the bank. When $\operatorname{VaR}$ is given by $V$, the rule can be written as

$$
E=V
$$

so that the ratio of $\mathrm{VaR}$ to equity stays constant. The idea is that the firm can cut back its asset exposure when the environment becomes more risky thereby bringing its Value-at-Risk back in line with this equity. Figure 5 is revealing in this respect. It plots the following three series:

- unit VaR

- the ratio of VaR to Equity

- leverage (the ratio of total assets to equity)

In other words, Figure 5 plots the leverage series together with the VaR normalized by book equity. It shows that the firms reacted to the spike in measured risks by sharply reducing their leverage. While the average leverage across the banks increased slightly until the Bear Stearns crisis in March 2008, it dropped by more than five standard deviations between the second and the fourth quarters of 2008. At the same time, the VaR to equity ratio barely changed. Thus, even as the unit VaR was fluctuating sharply, the VaR to equity ratio was moving much less, giving weight to the Value-at-Risk rule as a good approximation of the way that the firms were managing their risks. The evidence is that the banks in our sample were shedding risk exposures very sharply over the crisis period.

The analysis based on normalized time plots in Figures $4-5$ is further confirmed by the correlation analysis of quarterly growth rates in Table 1 . We see that leverage growth is strongly negatively correlated with shocks to the risk measures (unit VaR growth, and lagged implied volatility changes), but uncorrelated with the growth of the VaR to equity ratio. The evidence is that leveraged financial intermediaries manage their balance 
Table 1: Correlations of weighted average series. Each variable is the average weighted by lagged total assets across banks. The ${ }^{*}$ denotes significance at the 10 percent level, The ${ }^{* *}$ denotes significance at the 5 percent level, the ${ }^{* * *}$ denotes significance at the 1 percent level.

\begin{tabular}{lc}
\hline \hline & Quarterly Leverage Growth \\
\hline Quarterly VaR/E growth & 0.03 \\
Quarterly Unit VaR growth & $-0.33^{* *}$ \\
Quarterly CDS spread change & $-0.52^{* *}$ \\
Quarterly implied volatility changes (lagged) & $-0.31^{* *}$ \\
\hline \hline
\end{tabular}

sheets actively so as to maintain Value-at-Risk equal to their equity in the face of rapidly changing market conditions.

Evidence at the individual firm level can be obtained through panel regressions. Table 2 presents evidence from the panel regressions for the five Wall Street investment banks, although the panel is unbalanced due to the failure of Bear Stearns in March 2008, Lehman Brothers in September 2008 and the merger of Merrill Lynch with Bank of America in 2008. The regressions examine the implication of the Value-at-Risk rule where leverage $L$ satisfies $L=A / E=1 / v$ so that

$$
\ln L=-\ln v
$$

where $v$ is unit VaR (Value-at-Risk per dollar of assets). When log leverage is regressed on the log of the unit VaR, the VaR rule would predict that the coefficient is negative and equal to -1 .

In Table 2, the first column reports the simple OLS regression for the pooled sample. Columns 2 to 4 are fixed effects panel regressions, where columns 3 and 4 use clustered standard errors at the bank level. Column 5 uses the GEE (generalized estimation equation) $\operatorname{method}^{7}$ for averaged effects across banks described in Hardin and Hilbe (2003). The GEE method attempts to estimate the average response over the population ("populationaveraged" effects) when the error structure is not known. The parantheses report either

\footnotetext{
${ }^{7}$ http://en.wikipedia.org/wiki/Generalized_estimating_equation
} 
Table 2: Panel regressions for leverage. This table reports regressions for the determinant of leverage of the five US broker dealers. The dependent variable is log leverage. Column 1 is the OLS regression for the pooled sample. Columns 2 to 4 are fixed effects panel regressions. 3 and 4 use clustered standard errors at the bank level. Column 5 uses the GEE (generalized estimation equation) method for averaged effects across banks (Hardin and Hilbe (2003)). t statistics are in parantheses in columns 1 to 4 . Column 5 reports z scores.

\begin{tabular}{|c|c|c|c|c|c|}
\hline \multicolumn{6}{|c|}{ Dependent variable: $\log$ leverage ( $t$ or $z$ stat in parantheses) } \\
\hline & 1 & 2 & 3 & 4 & 5 \\
\hline \multirow[t]{2}{*}{$\log$ unit VaR } & $-0.479^{* * *}$ & $-0.384^{* * *}$ & $-0.384^{* *}$ & $-0.421^{* *}$ & $-0.426^{* * *}$ \\
\hline & $(-11.08)$ & $(-9.2)$ & $(-2.17)$ & $(-2.99)$ & $(-3.12)$ \\
\hline \multirow[t]{2}{*}{ implied vol } & & & & 0.002 & 0.002 \\
\hline & & & & $(0.85)$ & $(0.87)$ \\
\hline \multirow[t]{2}{*}{ constant } & -1.089 & -0.247 & -0.247 & -0.630 & -0.689 \\
\hline & $(-2.82)$ & $(-0.66)$ & $(-0.16)$ & $(-0.53)$ & $(-0.59)$ \\
\hline$R^{2}$ & 0.40 & 0.32 & 0.32 & 0.34 & \\
\hline obs & 185 & 185 & 185 & 185 & 185 \\
\hline$F$ or $\chi^{2}$ & 122.7 & 84.6 & 4.71 & 115.7 & 337.8 \\
\hline est. method & OLS & $\mathrm{FE}$ & $\mathrm{FE}$ & $\mathrm{FE}$ & GEE \\
\hline clust. err & & $\mathrm{N}$ & $\mathrm{Y}$ & $\mathrm{Y}$ & $\mathrm{Y}$ \\
\hline
\end{tabular}

the $t$ statistic (for columns 1 - 4) or the $z$-score (column 5).

We see that the coefficient on log unit VaR is negative and significantly different from zero throughout, although they fall short of the predicted magnitude of -1 . Translated in terms of risk premiums, leverage is high in boom times when the risk premium (unit $\mathrm{VaR}$ ) is low. For macro applications that are concerned with lending decisions by the bank or for the applications to runs on banks and other financial intermediaries as in Geanakoplos (2009) and Gorton and Metrick (2012), the procyclical nature of leverage plays an important role in the analysis.

A further consequence of the VaR rule can be derived from equation (4) which implies that

$$
\ln L_{t}-\ln L_{t-1}=-\left(\ln v_{t}-\ln v_{t-1}\right)
$$

so that the scatter chart of leverage changes against unit VaR changes should have slope -1. Figure 6 plots log changes in leverage against log changes in Unit VaR. We can see 


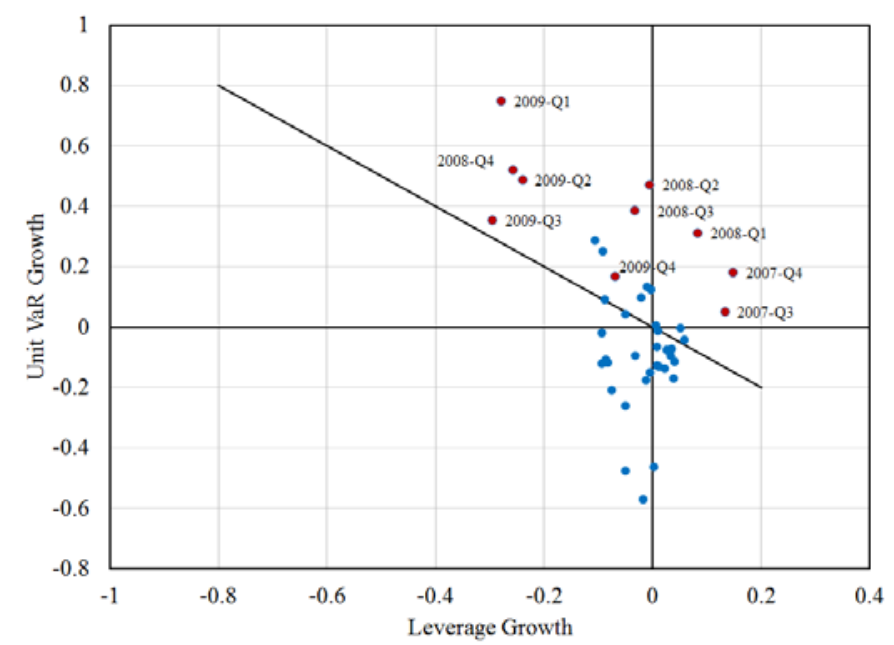

Figure 6: Shocks to Risk and Adjustments to Leverage. This figure plots the annual growth rate in Unit VaR against the annual growth rate in Leverage. The variables are weighted by lagged total assets. The diagonal line has slope -1 . The red dots correspond to the quarters during the financial crisis.

two distinct regimes in the figure. During the financial crisis from the third quarter of 2007 through the fourth quarter of 2009 , the slope of the scatter is close to -1 , although we do not fully capture the feature that the intercept should be zero. Bearing in mind that these are annual growth rates, we can see from the horizontal scale of Figure 6 that the deleveraging was very substantial, indicating large balance sheet contractions.

Our findings point to the VaR rule being an important benchmark to consider in how leverage is chosen by the financial intermediaries in our sample, at least as a first hypothesis. We now turn to a possible theoretical rationale for the VaR rule based on a standard contracting framework.

\section{Contracting Framework}

Having confirmed the promising nature of the Value-at-Risk rule as a rule of thumb for bank behavior, we turn our attention to providing possible microfoundations for such a rule. Our approach is guided by the need to select the simplest possible framework that could rationalize the behavior of the intermediaries in our sample, relying only on 
standard building blocks. There should be no presumption that the approach developed below is the only such microfoundation. However, the spirit of the exercise is to start from very familiar building blocks, and see how far standard arguments based on these building blocks will yield observed behavior.

Our approach is to consider the contracting problem between an intermediary and uninsured wholesale creditors to the intermediary. We may think of the intermediary as a Wall Street investment bank and the creditor as another financial institution that lends to the investment bank on a collateralized basis. We build on the Holmström and Tirole (1997) model of moral hazard but focus attention on the risk choice by the borrower. We do not address why the contract takes the form of debt, and rely on other formulations that argue for the optimality of debt (such as Innes (1990), Gale and Hellwig (1985) or DeMarzo and Duffie (1999)). Instead, our focus is on the limits on leverage as the constraint placed by the (uninsured) wholesale creditor on the intermediary, thereby limiting the size of balance sheet for any given level of capital of the borrower. ${ }^{8}$

With the application to credit availability in mind, we will formulate the framework so that we can examine shifts in the payoff parameters that mimic the shifts in economic conditions over the business cycle. This entails examining a family of payoff distributions that are indexed by a parameter $\theta$ that indicates the stage of the business cycle. High $\theta$ corresponds to boom times, while low $\theta$ corresponds to busts. Our interest is on how the leverage implied by the contracting outcome depends on $\theta$.

We find that under quite general conditions on the payoff distribution that are appropriate for extreme outcomes (such as the failure of financial intermediaries), we find that the probability of default of the financial intermediary is invariant to shifts in $\theta$. In

\footnotetext{
${ }^{8}$ This is a theme that is well-known in the banking literature on minimum capital requirements that counteract the moral hazard created by deposit insurance (Michael Koehn and Anthony Santomero (1980), Daesik Kim and Santomero (1988), Jean-Charles Rochet (1992)). Gabriella Chiesa (2001), Guillaume Plantin and Rochet (2006) and Vittoria Cerasi and Rochet (2007) have further developed the arguments for regulatory capital not only in banking sector, but in the insurance sector as well.
} 
other words, the borrower (the bank) is induced to shrink or expand the balance sheet as part of the solution so that its failure probability is constant, irrespective of the risk environment. In short, we find that the contracting outcome is that predicted by the Value-at-Risk rule.

In some special cases, we can even solve explicitly for the fixed probability of default in the Value-at-Risk rule as a function of the underlying parameters of the contracting problem. In this way, we provide a microfoundations of the behavior inherent in the VaR rule from a standard contracting problem.

It is worth reiterating that there should be no presumption that the microfoundation offered here is the only way to rationalize the Value-at-Risk rule. Nevertheless, we can take some comfort in the familiarity of the framework that yields the main result. We regard this result as being potentially an important step in understanding the procyclicality of the financial system. When the economic environment is benign, the intermediary will expand its balance sheet in accordance with its target probability of default. But when overall risk in the financial system increases, the intermediary cuts its asset exposure in order to maintain the same probability of default.

\subsection{Set up}

We now describe the contracting model in more detail. There is one principal and one agent. Both the principal and agent are risk-neutral. The agent is a financial intermediary that finances its operation through collaterateralized borrowing. For ease of reference, we will simply refer to the agent as the "bank". The principal is an (uninsured) wholesale creditor to the bank. A bank is both a lender and a borrower, but it is the bank's status as the borrower that will be important here.

There are two dates - date 0 and date 1 . The bank lends by purchasing assets at date 0 and receives its payoffs and repays its creditors at date 1 . The bank starts with

fixed equity $E$, and chooses the size of its balance sheet. We justify this assumption by 
reference to the scatter chart encountered already in Figures 2 and 3. Denote by $A$ the market value of assets of the bank. The notional value of the assets is $(1+\bar{r}) A$, so that each dollar's worth of assets acquired at date 0 promises to repay $1+\bar{r}$ dollars at date 1 .

The assets are funded in a collateralized borrowing arrangement, such as a repurchase agreement. The bank sells the assets worth $A$ for price $D$ at date 0 , and agrees to repurchase the assets at date 1 for price $\bar{D}$. Thus, the difference $\bar{D}-D$ represents the promised interest payment to the lender and $(\bar{D} / D)-1$ can be interpreted as the repo interest rate. Equity financing meets the gap $A-D$ between assets acquired and debt financing. Let $E$ be the value of equity financing. The balance sheet in market values at date 0 is therefore

\begin{tabular}{|c|c|}
\hline Assets & Liabilities \\
\hline Assets $A$ & $\begin{array}{c}\text { Debt } D \\
\text { Equity } E\end{array}$ \\
\hline
\end{tabular}

The notional value of the securities is $(1+\bar{r}) A$, and the notional value of debt is the repurchase price $\bar{D}$. Thus, the balance sheet in notional values can be written as

\begin{tabular}{|c|c|}
\hline Assets & Liabilities \\
\hline Assets $A(1+\bar{r})$ & $\begin{array}{c}\text { Debt } \bar{D} \\
\text { Equity } \bar{E}\end{array}$ \\
\hline
\end{tabular}

where $\bar{E}$ is the notional value of equity that sets the two sides of the balance sheet equal. The bank has the choice between two types of assets - good securities and substandard securities. For each dollar invested at date 0 , the bank can buy notional value of $1+\bar{r}$ of either security. However, for each dollar invested at date 0 the good security has expected payoff

$$
1+r_{H}
$$

with outcome density $f_{H}($.$) . The bad security has expected payoff 1+r_{L}$ with density 
$f_{L}($.$) . We assume that$

$$
r_{L}<0<r_{H}
$$

so that investment in the bad security is inefficient. We assume that the bank's balance sheet is scalable in the sense that asset payoffs satisfy constant returns to scale.

Although the bad securities have a lower expected payoff, it has higher upside risk relative to the good project in the following sense. Denote by $F_{H}($.$) the cumulative$ distribution function associated with $f_{H}$ and let $F_{L}($.$) be the cdf associated with f_{L}$. We suppose that $F_{H}$ cuts $F_{L}$ precisely once from below so that the distribution functions $F_{L}$ and $F_{H}$ when adjusted for the mean can be ordered in the sense of second order stochastic dominance (SOSD). Formally, there is $z^{*}$ such that $F_{H}\left(z^{*}\right)=F_{L}\left(z^{*}\right)$, and

$$
\left(F_{H}(z)-F_{L}(z)\right)\left(z-z^{*}\right) \geq 0
$$

for all z. The bank's initial endowment is its equity $E$. The bank decides on the total size of its balance sheet by taking on debt. The debt financing decision involves both the face value of debt $\bar{D}$ and its market value $D$. The optimal contract maximizes the bank's expected payoff by choice of $A, D$ and $\bar{D}$ with $E$ being the exogenous variable.

The fact that $E$ is the exogenous variable in our contracting setting goes to the heart of the procyclicality of lending and is where our paper deviates from previous studies. Here, our starting point is the evidence from the scatter charts (Figures 2 and 3) suggesting that intermediaries' equity is sticky even during boom times when leverage is expanding. The reasons for the stickiness of equity is beyond the scope of our investigation here, although it is closely related to the "slow-moving" nature of capital as discussed by Duffie (2010) in his 2009 AFA Presidential address. ${ }^{9}$

\footnotetext{
${ }^{9}$ The classic papers of Myers and Majluf (1984) and Jensen (1985) discuss some of the frictions that result in slow-moving capital. See also He and Krishnamurthy (2013) and Acharya, Shin and Yorulmazer (2013).
} 


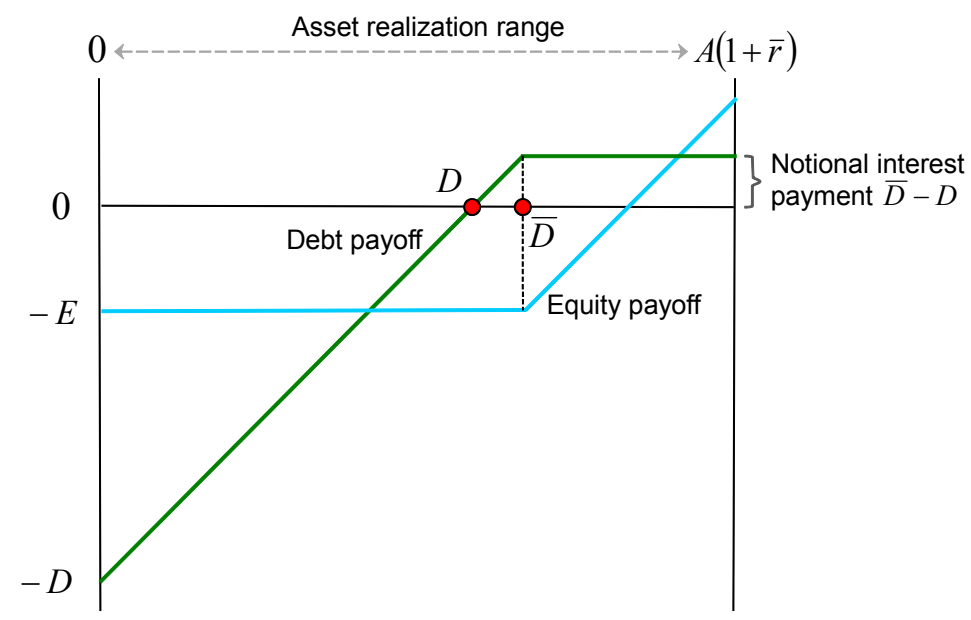

Figure 7: Net payoffs of the bank (equity holder) and the creditor to the bank (debt holder). $\bar{D}-D$ is the interest payment received by the creditor

\subsection{Contracting Outcome}

As noted by Merton (1974), the value of a defaultable debt claim with face value $\bar{D}$ is the price of a portfolio consisting of (i) cash of $\bar{D}$ and (ii) short position in a put option on the assets of the borrower with strike price $\bar{D}$. The net payoff of the creditor to the bank is illustrated in Figure 7. The creditor loses her entire stake $D$ if the realized asset value of the bank's assets is zero. However, if the realized asset value of the bank is $\bar{D}$ or higher, the creditor is fully repaid. We have $\bar{D}>D$, since the positive payoff when the bank does not default should compensate for the possibility that the creditor will lose in the case of default.

The borrower (i.e. the bank) is the residual claim holder, and its payoff is illustrated as the kinked convex function in Figure 7. The sum of the equity holder's payoff and the creditor's payoff gives the payoff from the total assets of the bank.

The solution of the contracting problem involves both the face value of debt $\bar{D}$ as well as the market value of debt $D$. The face value of debt has the interpretation of the strike price of the embedded option in the debt contract, and enters into the incentive compatibility constraint for the borrower (the bank), since the incentive constraint must 
limit the option value of limited liability. For the lender, the interest payment is given by $\bar{D}-D$, and so the participation constraint involves limiting the size of this gap. Given $\bar{D}$, the participation constraint determines $D$.

Finally, once $D$ is known, the scale of the investment given by $A$ can be determined from the balance sheet identity $A=D+E$ and the exogenous $E$.

\subsection{Creditor's Participation Constraint}

Denote by $\pi_{H}(\bar{D}, A)$ the price of the put option with strike price $\bar{D}$ on the portfolio of good securities whose current value is $A$. We assume that the market for assets is competitive, so that the option price satisfies constant returns to scale:

$$
\pi_{H}(\bar{D}, A)=A \pi_{H}\left(\frac{\bar{D}}{A}, 1\right)
$$

Similarly, $\pi_{L}(\bar{D}, A)=A \pi_{L}\left(\frac{\bar{D}}{A}, 1\right)$, for portfolios consisting of bad securities. Define $\bar{d}$ as the ratio of the promised repurchase price at date 1 to the market value of assets of the bank at date 0

$$
\bar{d} \equiv \bar{D} / A
$$

Hence $\bar{d}$ is the ratio of the notional value of debt to the market value of assets. Define:

$$
\pi_{H}(\bar{d}) \equiv \pi_{H}(\bar{d}, 1)
$$

so that $\pi_{H}(\bar{d})$ is the price of the put option on one dollar's worth of the bank's asset with strike price $\bar{d}$ when the bank's portfolio consists of good assets. $\pi_{L}(\bar{d})$ is defined analogously for portfolio of bad securities.

The creditor's initial investment is $D$, while the expected value of the creditor's claim is the portfolio consisting of (i) cash of $\bar{D}$ and (ii) short position in put option on the assets of the bank with strike price $\bar{D}$. The (gross) expected payoff of the creditor when 
the bank's assets are good is therefore

$$
\bar{D}-A \pi_{H}(\bar{d})=A\left(\bar{d}-\pi_{H}(\bar{d})\right)
$$

Since the creditor's initial stake is $D$, her net expected payoff is

$$
\begin{aligned}
U^{C}(A) & =\bar{D}-D-A \pi_{H}(\bar{d}) \\
& =A\left(\bar{d}-d-\pi_{H}(\bar{d})\right)
\end{aligned}
$$

where $d \equiv D / A$ is the ratio of the market value of debt to the market value of assets. The participation constraint for the creditor requires that the expected payoff is large enough to recoup the initial investment $D$. That is,

$$
\bar{d}-d-\pi_{H}(\bar{d}) \geq 0
$$

The term $\bar{d}-d$ is the promised interest payment to the creditor, so that the participation constraint stipulates that the interest payment should be sufficiently large to cover the value of the put option that the creditor is granting to the borrower.

\subsection{Bank's Incentive Compatibility Constraint}

The payoff of the borrower is given by the difference between the net payoffs for the bank's assets as a whole and the creditor's net payoff, given by $U^{C}$ in (12). Thus, the bank's payoff is

$$
U^{E}(A)=A(r-(\bar{d}-d)+\pi(\bar{d}))
$$

where $r \in\left\{r_{L}, r_{H}\right\}$, and $\pi(\bar{d}) \in\left\{\pi(\bar{d})_{L}, \pi(\bar{d})_{H}\right\}$. The bank's payoff consists of the asset payoff $r$, the value of the option $\pi(\bar{d})$ minus the promised interest payment $\bar{d}-d$. The optimal contract maximizes $U^{E}$ subject to the borrower's incentive compatibility constraint and the break-even constraint of the creditor. The expected payoff for the 
bank when the asset portfolio consists of the good asset is

$$
A\left(r_{H}-(\bar{d}-d)+\pi_{H}(\bar{d})\right)
$$

while the expected payoff from holding bad assets is $A\left(r_{L}-(\bar{d}-d)+\pi_{L}(\bar{d})\right)$, where $\pi_{L}(\bar{d})$ is the value of the put option on 1 dollar's worth of the bank's assets with strike price $\bar{d}$ when the bank holds bad assets. The incentive compatibility constraint is therefore

$$
\begin{aligned}
r_{H}-r_{L} & \geq \pi_{L}(\bar{d})-\pi_{H}(\bar{d}) \\
& =\Delta \pi(\bar{d})
\end{aligned}
$$

where $\Delta \pi(\bar{d})$ is defined as $\pi_{L}(\bar{d})-\pi_{H}(\bar{d})$. The term $\Delta \pi(\bar{d})$ is analogous to the private benefit of exerting low effort in the moral hazard model of Holmström and Tirole (1997). The bank trades off the greater option value of holding the riskier asset against the higher expected payoff from holding the good asset. The incentive compatibility constraint requires that the option value be small relative to the difference in expected returns.

Note that the IC constraint does not make reference to the market value of debt $d$, but only to the face value of debt $\bar{d}$. This reflects the fact that the IC constraint is a condition on the strike price of the embedded option. In order to derive the market value of debt (and hence market leverage), we must also use the IR constraint.

Given our assumptions on the densities governing the good and bad securities, we have the following preliminary result.

Lemma 1 The incentive compatibility constraint always binds, and there is a unique solution $\bar{d}^{*}$ for the notional value of debt.

Proof. From the result in option pricing due to Breeden and Litzenberger (1978), the price of the Arrow-Debreu contingent claim that pays 1 at $z$ and zero otherwise is given by the second derivative of the option price with respect to the strike price evaluated at z. Since both the principal and agent are risk-neutral, the state price is the probability. 


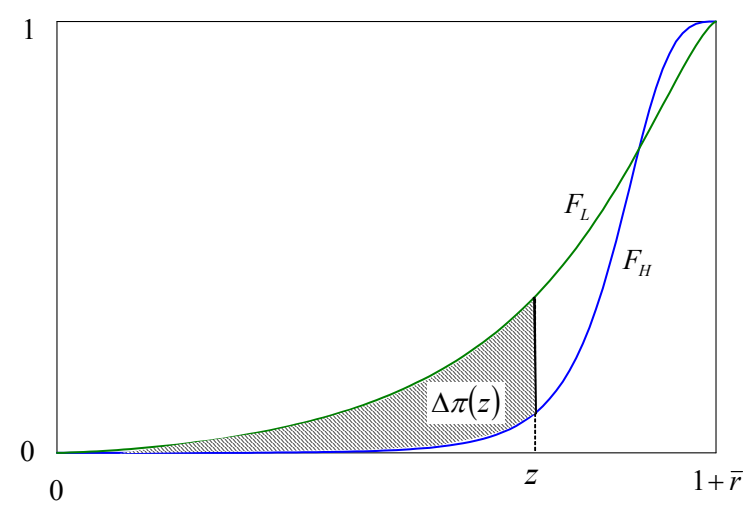

Figure 8: Private benefit in the moral hazard problem is the higher option value from limited liability given by $\Delta \pi(z)$ when default takes place at $z$.

Thus, we have

$$
\Delta \pi(z)=\int_{0}^{z}\left(F_{L}(s)-F_{H}(s)\right) d s
$$

as illustrated in Figure 8. Since $F_{H}$ cuts $F_{L}$ precisely once from below, $\Delta \pi(z)$ is increasing initially, is maximized at the point $z^{*}$ where $F_{H}=F_{L}$, and is then decreasing. Using integration by parts ${ }^{10}$ we have

$$
\begin{aligned}
\Delta \pi(1+\bar{r}) & =\int_{0}^{1+\bar{r}}\left(F_{L}(s)-F_{H}(s)\right) d s \\
& =\int_{0}^{1+\bar{r}}\left(1-F_{H}(s)\right) d s-\int_{0}^{1+\bar{r}}\left(1-F_{L}(s)\right) d s \\
& =\int_{0}^{1+\bar{r}} s f_{H}(s) d s-\int_{0}^{1+\bar{r}} s f_{L}(s) d s \\
& =r_{H}-r_{L}
\end{aligned}
$$

In other words, $\Delta \pi(z)$ approaches $r_{H}-r_{L}$ from above as $z \rightarrow 1+\bar{r}$. But from the notional balance sheet (7), dividing all elements by $A$ implies that $1+\bar{r}>\bar{d}$. Thus, $\Delta \pi(z)$ cuts $r_{H}-r_{L}$ precisely once, and there is a unique solution $\bar{d}^{*}$ to the incentive compatibility constraint (IC). This proves the lemma.

Lemma 1 gives the crucial leverage constraint for the bank arising from the haircut implied by the collateral requirement set by the creditor. We will see shortly how the

\footnotetext{
${ }^{10} \mathrm{We}$ are grateful to a referee for this proof.
} 
leverage constraint changes to shifts in the parameters characterizing the distribution over outcomes.

\subsubsection{Repo Interest Rate}

The notional debt ratio $\bar{d}^{*}$ that solves the bank's incentive compability constraint. The next step of the solution is to obtain the repo interest rate by using the break-even constraint for the lender. The lender's participation constraint (IR) is that the promised interest payment $\bar{d}-d$ is just sufficient to cover the value of the put option granted to the borrower.

$$
d=\bar{d}-\pi_{H}(\bar{d})
$$

We can then solve for the market value of debt $d$. Denoting by $d^{*}$ the market value of debt that solves the contracting problem, we have

$$
d^{*}=\bar{d}^{*}-\pi_{H}\left(\bar{d}^{*}\right)
$$

where $\bar{d}^{*}$ is the unique solution to the borrower's incentive compability constraint guaranteed by Lemma 1. The right hand side of (16) is the payoff of a creditor with a notional claim of $\bar{d}^{*}$. Hence, we can re-write (16) as

$$
d^{*}=\int_{0}^{1+\bar{r}} \min \left\{\bar{d}^{*}, s\right\} f_{H}(s) d s
$$

Clearly, $d^{*}$ is increasing in $\bar{d}^{*}$, so that the debt ratio in market values is increasing in the notional debt ratio $\bar{d}^{*}$.

\subsection{Balance Sheet Size}

Having tied down the bank's leverage through (16), the final step of the solution is to determine the scale of the bank's balance sheet given its initial equity $E$. Note from (13) 
that the bank's expected payoff is:

$$
U^{E}(A) \equiv A\left(r_{H}-\left(\bar{d}^{*}-d^{*}\right)+\pi_{H}\left(\bar{d}^{*}\right)\right)
$$

The expression inside the brackets is strictly positive, since the bank extracts the full surplus from the relationship. Hence, the bank's payoff is strictly increasing in $A$, and it maximizes the scale of the bank subject only to initial equity and the leverage constraint (16). Let $\lambda^{*}$ be the upper bound on leverage implied by $d^{*}$, defined as

$$
\lambda^{*} \equiv \frac{1}{1-d^{*}}
$$

Then, the bank chooses total balance sheet size given by:

$$
A=\lambda^{*} E
$$

We note the contrast between this feature of our model and the textbook discussion that either treats the asset size as fixed, or as evolving exogenously. Instead, in our model, it is equity that is the exogenous variable. For given equity $E$, total asset size $A$ is determined as $\lambda^{*} \times E$, where $\lambda^{*}$ is the maximum leverage permitted by the creditors in the contracting relationship. Thus, as $\lambda^{*}$ fluctuates, so will the size of the bank's balance sheet. In the next section, we link $\lambda^{*}$ to the Value-at-Risk, and will see that the model gives rise to the empirical features we documented in section $2 .^{11}$

\section{Value-at-Risk}

We come to our core result. With the application to credit availability in mind, we examine a family of payoff distributions indexed by a parameter $\theta$ that indicates the stage of the business cycle. High $\theta$ corresponds to boom times, while low $\theta$ corresponds

\footnotetext{
${ }^{11}$ Haircuts determine the maximum level of leverage that financial institutions can achieve. In the static set-up of our paper, institutions will always lever maximally. In practice, institutions might not lever maximally due to intertemporal considerations.
} 
to busts, and show how leverage and the probability of default varies with shifts in $\theta$.

We now turn to the risk environment. Since bank failure and the probabilities associated with Value-at-Risk are inherently concerned with extreme events, a general framework where all such extreme outcomes can be accommodated would provide an appropriate overall setting for our investigation.

The key result in our context is the Fisher-Tippett theorem from extreme value theory (EVT) that plays the benchmark role for extreme outcomes in the way that the central limit theorem plays for the limit of sums of i.i.d. random variables. The Fisher-Tippett theorem states if the maximum draw from a sequence of i.i.d. realizations of a random variable has a non-denerate limit, then any such limiting distribution belongs to the family of Generalized Extreme Value (GEV) distributions.

Fisher-Tippett Theorem. Suppose $X_{1}, \cdots, X_{n}$ are i.i.d. with maximum realization $M_{n}$. If there are $\left(a_{n}\right),\left(b_{n}\right)$ such that

$$
\lim _{n \rightarrow \infty} \operatorname{Pr}\left(\frac{M_{n}-b_{n}}{a_{n}} \leq z\right)=G(z)
$$

for non-degenerate $G(z)$, then

$$
G(z)=\exp \left\{-\left(1+\xi\left(\frac{z-\theta}{\sigma}\right)\right)^{-\frac{1}{\xi}}\right\}
$$

for parameters $\xi, \theta \in \mathbb{R}, \sigma>0$ where $1+\xi\left(\frac{z-\theta}{\sigma}\right)>0$

The version of the Fisher-Tippett theorem given above is due to Gnedenko (1948), and is discussed in Embrechts, Kluppelberg and Mikosch (1997, chapter 3). The distribution function (21) is the GEV distribution. Thus, under quite general conditions on the payoff distribution that are appropriate for extreme outcomes (such as the failure of financial intermediaries), the GEV distribution would be the appropriate parameterization of the distributions $F_{H}$ and $F_{L}$ underlying our contracting problem. Thus, we parameterize $F_{H}$ 


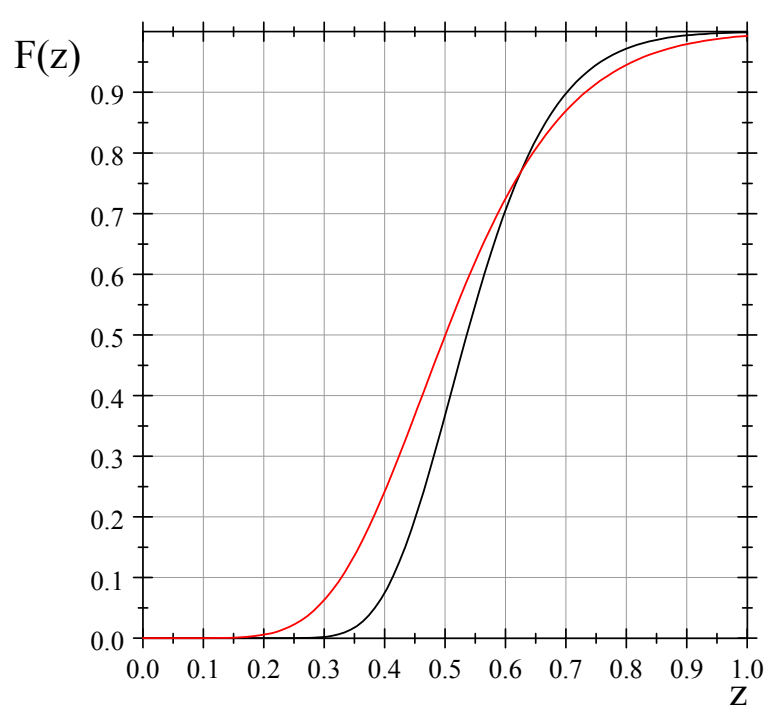

Figure 9: Distribution functions $F_{L}$ and $F_{H}$ for $\xi=0.1, \theta=0.5, \sigma=0.1, k=0.05$, and $m=1.4$. The dark line indicates $F_{H}$ and the lighter line indicates $F_{L}$.

and $F_{L}$ as:

$$
F_{H}(z)=\exp \left\{-\left(1+\xi\left(\frac{z-\theta}{\sigma}\right)\right)^{-\frac{1}{\xi}}\right\}, \quad F_{L}(z)=\exp \left\{-\left(1+\xi\left(\frac{z-(\theta-k)}{m \sigma}\right)\right)^{-\frac{1}{\xi}}\right\}
$$

where $k>0$ and $m>1$. The location parameter $\theta$ has the interpretation as the stage of the business cycle with high $\theta$ indicating booms and low $\theta$ indicating busts. The outcome distribution association with the choice of the bad action is shifted to the left by constant $k$ and has a scaling parameter $\sigma^{\prime}=m \sigma>\sigma$. This formulation is consistent with our assumption that the mean of $F_{L}$ is lower, and has greater dispersion $m \sigma$. Figure 9 plots $F_{H}$ and $F_{L}$ for the parameters indicated. The main result of our paper can be stated as follows.

Proposition 1 Suppose $F_{H}$ and $F_{L}$ are given by (22). Then, the solution to the contracting problem entails probability of default $\alpha(\theta)$ that is invariant to $\theta$.

The proposition states that the probability of default by the bank is invariant to shifts in $\theta$. In other words, the solution to the contracting problem entails the Valueat-Risk rule, under which the bank's leverage adjusts so as to leave the probability of 


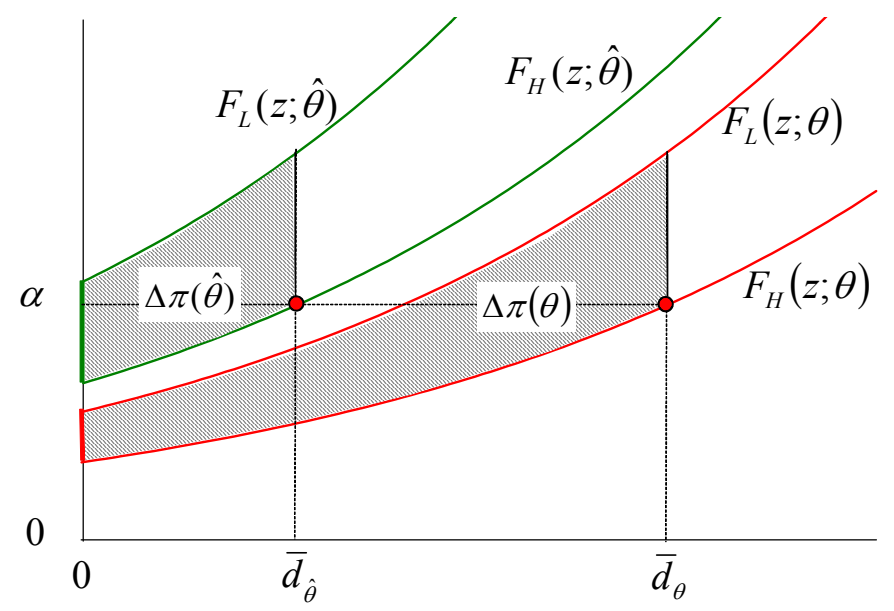

Figure 10: Invariance of the probability of default $\alpha$. As the location parameter shifts from $\theta$ to $\hat{\theta}$, the bank's leverage falls leaving default probability unchanged at $\alpha$.

default constant. Figure 10 illustrates the key invariance property of default over the cycle, where the probability of default does not depend on $\theta$. In Figure 10, as the location parameter shifts from $\theta$ to $\hat{\theta}$, the bank's leverage falls leaving default probability unchanged at $\alpha$, even though the underlying distribution functions have shifted.

Steps in the proof of the Proposition are given in the appendix, but we give the key steps here. In the appendix, we show that the temptation payoff $\Delta \pi$ at $\theta$ can be written as

$$
\Delta \pi\left(\bar{d}^{*}(\theta)\right)=\sigma \times \int_{m^{\frac{1}{\xi}}\left((\ln (1 / \alpha(\theta)))^{-\xi}+\xi \frac{k}{\sigma}\right)^{-\frac{1}{\xi}}}^{\ln (1 / \alpha(\theta))} t^{-(1+\xi)} e^{-t} d t
$$

where $\alpha(\theta)$ is the probability of default by the bank in the contracting outcome at $\theta$. Next, the mean of the GEV distribution has the form $\theta+\sigma H(\xi)$ where $H(\xi)$ is a function solely of $\xi .^{12}$ Hence

$$
\begin{aligned}
r_{H}(\theta)-r_{L}(\theta) & =\theta+\sigma H(\xi)-(\theta-k)-m \sigma H(\xi) \\
& =k-(m-1) H(\xi)
\end{aligned}
$$

\footnotetext{
${ }^{12}$ See the wikipedia page http://en.wikipedia.org/wiki/Generalized_extreme_value_distribution
} 
which is invariant to $\theta$. Then the IC constraint defines an equation for the probability of default $\alpha$ that is invariant to $\theta$, given by

$$
\text { constant }=\int_{m^{\frac{1}{\xi}}\left((\ln (1 / \alpha(\theta)))^{-\xi}+\xi \frac{k}{\sigma}\right)^{-\frac{1}{\xi}}}^{\ln (1 / \alpha(\theta))} t^{-(1+\xi)} e^{-t} d t
$$

Thus, the location parameter $\theta$ enters the solution solely through the probability of default $\alpha$. Since (25) defines $\alpha$ implicitly, the probability of default is invariant to $\theta$. This proves Proposition 1.

\subsection{Closed Form Solution}

The probability of default $\alpha$ in the VaR rule is determined by the fundamentals of the contracting problem, and in some cases, we can obtain an explicit solution for $\alpha$. One such case is when $\xi=-1$ and $m \rightarrow 1$. Then, we have

$$
F_{H}(z)=\exp \left\{\frac{z-\theta}{\sigma}-1\right\}, \quad F_{L}(z)=\exp \left\{\frac{z-(\theta-k)}{\sigma}-1\right\}
$$

and we have $F_{L}(z ; \theta) / F_{H}(z ; \theta)=e^{\frac{k}{\sigma}}>1$. The temptation payoff can be written as

$$
\begin{aligned}
\Delta \pi(z ; \theta) & =\int_{-\infty}^{z}\left(F_{L}(s ; \theta)-F_{H}(s ; \theta)\right) d s \\
& =\left(e^{\frac{k}{\sigma}}-1\right) \int_{-\infty}^{z} F_{H}(s ; \theta) d s \\
& =\left(e^{\frac{k}{\sigma}}-1\right) \cdot \sigma F_{H}(z ; \theta)
\end{aligned}
$$

From the IC constraint $\Delta \pi\left(\bar{d}^{*} ; \theta\right)=r_{H}-r_{L}$ so that

$$
\left(e^{\frac{k}{\sigma}}-1\right) \cdot \sigma F_{H}\left(\bar{d}^{*} ; \theta\right)=r_{H}-r_{L}
$$

From (27) and (28), the probability of default $\alpha(\theta)$ is given by

$$
\alpha(\theta)=F_{H}\left(\bar{d}^{*} ; \theta\right)=\frac{r_{H}-r_{L}}{\sigma\left(e^{\frac{k}{\sigma}}-1\right)}
$$


which is invariant to $\theta$. What's more, we can solve for $\alpha$ so that we can fully endogenize the Value-at-Risk confidence level $c=1-\alpha$ in terms of parameters of moral hazard problem. Together with the definition of $\alpha(\theta)$ as the probability of default,

$$
\alpha(\theta)=F_{H}\left(\bar{d}^{*} ; \theta\right)=\exp \left\{\frac{\bar{d}^{*}-\theta}{\sigma}-1\right\}=\frac{r_{H}-r_{L}}{\sigma\left(e^{\frac{k}{\sigma}}-1\right)}
$$

We thus have an explicit solution for the probability of default $\alpha$. We can also solve explicitly for the debt ratio $\bar{d}^{*}$

$$
\bar{d}^{*}=\theta+\sigma+\sigma \ln \left(\frac{r_{H}-r_{L}}{\sigma\left(e^{k / \sigma}-1\right)}\right)
$$

We see that $\bar{d}^{*}$ is increasing in $\theta$, so that leverage increases in boom times and decreases in busts. Leverage is procyclical.

As a cross check, we can verify that our closed form solution can be obtained from the general solution given by (25). Note that when $\xi=-1$, we have

$$
\begin{aligned}
\frac{r_{H}-r_{L}}{\sigma} & =\int_{m^{-1}\left(\ln (1 / \alpha)-\frac{k}{\sigma}\right)}^{\ln (1 / \alpha)} e^{-t} d t \\
& =\left[-e^{-t}\right]_{m^{-1}\left(\ln (1 / \alpha)-\frac{k}{\sigma}\right)}^{\ln (1 / \alpha)} \\
& =\alpha\left((\alpha e)^{-\frac{m-1}{m}} e^{\frac{k}{m \sigma}}-1\right)
\end{aligned}
$$

Then for $m \rightarrow 1$, we have $\left(r_{H}-r_{L}\right) / \sigma=\alpha\left(e^{\frac{k}{\sigma}}-1\right)$ so that $\alpha$ has the closed-form solution given by (30). We can thus fully endogenize the confidence level of the Valueat-Risk constraint through the underlying moral hazard problem.

\section{Concluding Remarks}

In this paper, we have employed perhaps the simplest contracting model for the determination of leverage and balance sheet size for financial intermediaries, and have examined the conditions under which the Value-at-Risk rule emerges from the contracting outcome. 
Our framework provides one possible microeconomic foundation for the widespread use of the Value-at-Risk rule among financial institutions. Our setup sheds light on the extent to which leverage decisions are the constraints that creditors impose on debtors.

The procyclical nature of leverage is a feature that is potentially at odds with many standard portfolio decision rules. For instance, for an investor with log utility, the leverage of the investor is monotonic in the Sharpe ratio of the risky security, so that leverage is high when the risk premium is high (Merton (1969)). In other words, for investors with log utility, leverage is countercyclical. Xiong (2001), He and Krishnamurthy (2013) and Brunnermeier and Sannikov (2011) are recent contributions that use the log utility formulation and hence which have the feature that leverage is countercyclical.

We have discussed the difference between the notion of leverage defined in terms of the total assets of the bank and in terms of its enterprise value. Which of the two notions of leverage is relevant depends on the context and the question being addressed. Enterprise value has to do with how much the bank is worth, while assets have to do with how much the bank lends. We have argued that for questions to do with the supply of credit by banks, total assets and book leverage are key. Financial stability questions that deal with runs on banks by other banks are also about lending, in this case by one bank to another bank. Hence, again, book leverage is the key notion. The differences between behavior implied by the VaR rule and log preferences matter for those macro applications that focus on the availability of credit. The supply of credit by banks is about the portfolio of the banks - i.e. its book asset, rather than its enterprise value, and so procyclical leverage has a direct impact on the supply of credit through shrinking lending. Nuño and Thomas (2011) and Adrian and Boyarchenko (2012) are examples of macroeconomic models with financial sectors that replicates the procyclicality of leverage.

Our modeling framework provides microfoundations to the limits of arbitrage and the fire sale literatures. Shleifer and Vishny (1992) provide an early model of fire sales, where 
equilibrium asset values depend on the debt capacity of the sector of the economy that invests in such assets. Shleifer and Vishny (1997) point out that the financial constraints of financial intermediaries affect equilibrium asset valuations. More recently, many studies have either implicitly or explicitly assumed a Value-at-Risk constraint in modeling the management of financial institutions. Our paper contributes to this literature by providing microfoundations for the pervasive use of Value-at-Risk type rules. Gromb and Vayanos (2002) construct a model of intermediary capital, where constraints on the intermediary can induce excessive risk taking, as intermediaries are not internalizing that their fire sales tighten margin constraints of other arbitrageurs. Gromb and Vayanos (2010) provide conditions when the presence of intermediaries stabilize or destabilize equilibrium asset prices. Brunnermeier and Pedersen (2009) introduce margin constraints that follow a Value-at-Risk rule, and stress the interaction of market and funding liquidity. Oehmke (2008 and 2009) studies the speed and the spreading of price deviations when arbitrageurs face Value-at-Risk or other risk management constraints.

To be sure, showing that the $V a R$ rule is the outcome of a contracting model says little about the desirability of the widespread adoption of such practices from the point of view of macroeconomic efficiency. Indeed, risk management tools such as Value-atRisk that solve bilateral incentive frictions can generate spillover effects across financial institutions. The leveraging and deleveraging cycle and associated fluctuations in market risk premiums are likely to be influenced by the widespread adoption of risk management rules (Shin (2010)).

In a system context, fluctuations in leverage have far-reaching effects. To the extent that the financial system as a whole holds long-term, illiquid assets financed by short-term liabilities, any tensions resulting from a sharp increase in risk will show up somewhere in the system. Even if some institutions can adjust down their balance sheets flexibly in response to the greater stress, there will be some pinch points in the system that will 
be exposed by the distressed conditions. In effect, a generalized fall in the permitted leverage in the financial system can lead to a "run" on a particular institution that has funded long-lived illiquid assets by borrowing short. Developments of our techniques may be useful in richer setting with more complex intermediation relationships. 


\section{A Appendix}

In this appendix, we provide the steps in the proof of Proposition 1 . Consider the Generalized Extreme Value (GEV) distribution given by

$$
G(z)=\exp \left\{-\left(1+\xi\left(\frac{z-\theta}{\sigma}\right)\right)^{-\frac{1}{\xi}}\right\}
$$

We would like the expression for the integral of the GEV distribution. As a first step, consider the incomplete gamma function $\Gamma(x, y)$ defined as

$$
\Gamma(x, y) \equiv \int_{y}^{\infty} t^{x-1} e^{-t} d t
$$

where

$$
\begin{aligned}
& x=-\xi \\
& y=\left(1+\xi\left(\frac{z-\theta}{\sigma}\right)\right)^{-\frac{1}{\xi}}
\end{aligned}
$$

Note that

$$
\begin{aligned}
\frac{d y}{d z} & =-\frac{1}{\xi}\left(1+\xi\left(\frac{z-\theta}{\sigma}\right)\right)^{-\frac{1}{\xi}-1} \cdot \frac{\xi}{\sigma} \\
& =-\frac{1}{\sigma}\left(1+\xi\left(\frac{z-\theta}{\sigma}\right)\right)^{-\frac{1}{\xi}}\left(1+\xi\left(\frac{z-\theta}{\sigma}\right)\right)^{-1} \\
& =-\frac{1}{\sigma} y^{\xi+1}
\end{aligned}
$$

Hence

$$
\begin{aligned}
\frac{d}{d z} \Gamma(x, y) & =\frac{d}{d y} \Gamma(x, y) \cdot \frac{d y}{d z} \\
& =-y^{x-1} e^{-y} \cdot\left(-\frac{1}{\sigma} y^{\xi+1}\right) \\
& =y^{-\xi-1} e^{-y} \cdot \frac{1}{\sigma} y^{\xi+1} \\
& =\frac{1}{\sigma} e^{-y} \\
& =\frac{1}{\sigma} G(z)
\end{aligned}
$$


Hence the indefinite integral of $G(z)$ is:

$$
\int \exp \left\{-\left(1+\xi\left(\frac{z-\theta}{\sigma}\right)\right)^{-\frac{1}{\xi}}\right\} d z=\sigma \Gamma(x, y)+\text { constant }
$$

Define $y(z, \theta, \sigma)$ as

$$
y(z, \theta, \sigma) \equiv\left(1+\xi\left(\frac{z-\theta}{\sigma}\right)\right)^{-\frac{1}{\xi}}
$$

Let $\alpha$ be the probability of default for the bank. Then

$$
\alpha=\exp \left\{-\left(1+\xi\left(\frac{\bar{d}^{*}-\theta}{\sigma}\right)\right)^{-\frac{1}{\xi}}\right\}=e^{-y\left(\bar{d}^{*}, \theta, \sigma\right)}
$$

so that $y\left(\bar{d}^{*}, \theta, \sigma\right)=-\ln \alpha=\ln (1 / \alpha)$. Now, consider the expression for the temptation payoff for the bad action in the moral hazard problem for the bank. The temptation payoff to risk-shifting is the additional option value given by the bad action $L$. The option values of $L$ and $H$ are given, respectively, by

$$
\begin{aligned}
& \int_{0}^{\bar{d}^{*}} F_{H}(z, \theta) d z=\int_{-\infty}^{\bar{d}^{*}} \exp \left\{-\left(1+\xi\left(\frac{z-\theta}{\sigma}\right)\right)^{-\frac{1}{\xi}}\right\} d z \\
& \int_{0}^{\bar{d}^{*}} F_{L}(z, \theta) d z=\int_{-\infty}^{\bar{d}^{*}} \exp \left\{-\left(1+\xi\left(\frac{z-(\theta-k)}{m \sigma}\right)\right)^{-\frac{1}{\xi}}\right\} d z
\end{aligned}
$$

where $m>1$ and $k>0$. The temptation payoff in the moral hazard problem is given by

$$
\begin{aligned}
\Delta \pi(\theta) & =\int_{0}^{\bar{d}^{*}}\left(F_{L}(z, \theta)-F_{H}(z, \theta)\right) d z \\
& =\sigma[\Gamma(-\xi, y(z, \theta-k, m \sigma))]_{-\infty}^{\bar{d}^{*}}-\sigma[\Gamma(-\xi, y(z, \theta, \sigma))]_{-\infty}^{\bar{d}^{*}} \\
& =\sigma \int_{y\left(\bar{d}^{*}, \theta-k, m \sigma\right)}^{\infty} t^{-(1+\xi)} e^{-t} d t-\sigma \int_{y\left(\bar{d}^{*}, \theta, \sigma\right)}^{\infty} t^{-(1+\xi)} e^{-t} d t \\
& =\sigma \int_{y\left(\bar{d}^{*}, \theta-k, m \sigma\right)}^{y\left(\bar{d}^{*}, \theta, \sigma\right)} t^{-(1+\xi)} e^{-t} d t
\end{aligned}
$$

Meanwhile, we know that $y\left(\bar{d}^{*}, \theta, \sigma\right)=\ln (1 / \alpha)$. Also, by re-arranging the expression:

$$
y\left(\bar{d}^{*}, \theta-k, m \sigma\right)=\left(1+\xi\left(\frac{z-(\theta-k)}{m \sigma}\right)\right)^{-\frac{1}{\xi}}
$$


we have

$$
y\left(\bar{d}^{*}, \theta-k, m \sigma\right)=m^{\frac{1}{\xi}}\left((\ln (1 / \alpha))^{-\xi}+\xi \frac{k}{\sigma}\right)^{-\frac{1}{\xi}}
$$

Therefore, from (34), we have

$$
\Delta \pi(\theta)=\sigma \times \int_{m^{\frac{1}{\xi}}\left((\ln (1 / \alpha))^{-\xi}+\xi \frac{k}{\sigma}\right)^{-\frac{1}{\xi}}}^{\ln (1 / \alpha)} t^{-(1+\xi)} e^{-t} d t
$$

We see from (35) that the temptation payoff $\Delta \pi(\theta)$ is a function of $\theta$ solely through its effect on the probability of default $\alpha$. 


\section{References}

Acharya, V., H. S. Shin and T. Yorulmazer (2013) "Theory of Arbitrage Capital," Review of Corporate Finance Studies, 2 (1): 62-97.

Adrian, T. and N. Boyarchenko (2012) "Intermediary Leverage Cycles and Financial Stability," Federal Reserve Bank of New York Staff Report $56 \%$.

Adrian, T. and H. S. Shin (2010) "Liquidity and Leverage," Journal of Financial Intermediation 19(3), pp. 418-437.

Ang, A., S. Gorovyy and G. van Inwegen (2011) "Hedge Fund Leverage," Journal of Financial Economics 102(1), pp. 102-126.

Ball, Ray, Jayaraman, Sudarshan and Shivakumar, Lakshmanan (2012) "Mark-to-Market Accounting and Information Asymmetry in Banks" Chicago Booth Research Paper No. 12-35; LBS Working Paper, http://ssrn.com/abstract=1947832

Bischof, Jannis, Ulf Brüggemann and Holger Daske (2011) "Fair Value Reclassifications of Financial Assets During the Financial Crisis" http://papers.ssrn.com/sol3/papers.cfm?abstract_id=1628843

Breeden, D. and R. Litzenberger (1978) "Prices of State-Contingent Claims Implicit in Option Prices," Journal of Business 51(4), pp. 621-651.

Brunnermeier, M. and L. Pedersen (2009) "Market Liquidity and Funding Liquidity," Review of Financial Studies 22(6), pp. 2201-2238.

Brunnermeier, M. and Y. Sannikov (2011) "The i-Theory of Money" working paper, Princeton University.

Cerasi, V. and J.-C. Rochet (2007) "Solvency Regulation and Credit Risk Transfer," working paper, Toulouse University.

Chiesa, G. (2001) "Incentive-Based Lending Capacity, Competition, and Regulation in Banking," Journal of Financial Intermediation 10(1), pp. 28-53.

DeMarzo, Peter and Darrell Duffie (1999) "A Liquidity-based Model of Security Design" Econometrica 67(1), 65-99

Duffie, Darrell (2010) "Presidential Address: Asset Price Dynamics with Slow-Moving Capital" Journal of Finance, 64(4) 1237 - 1267

Embrechts, P., C. Kluppelberg, and T. Mikosch (1997) Modelling Extreme Events for Insurance and Finance, Springer-Verlag, Berlin

Gale, Douglas and Martin Hellwig (1985) "Incentive-Compatible Debt Contracts: The One-Period Problem" Review of Economic Studies 52 (4): 647-663. 
Geanakoplos, John (2009) "The Leverage Cycle" NBER Macroeconomics Annual 2009, In D. Acemoglu, K. Rogoff and M. Woodford, eds., NBER Macroeconomic Annual 2009, 24, 1-65, University of Chicago Press, 2010.

Gnedenko, B. (1948) "On a Local Limit Theorem of the Theory of Probability," Uspekhi Matematicheskikh Nauk 3(3), pp. 187-194.

Gorton, Gary and Andrew Metrick (2012) "Securitized Banking and the Run on Repo" Journal of Financial Economics, 104(3), 425-451.

Gromb, D. and D. Vayanos (2002) "Equilibrium and Welfare in Markets with Financially Constrained Arbitrageurs," Journal of Financial Economics 66(2-3), pp. 361-407.

Gromb, D. and D. Vayanos (2010) "A Model of Financial Market Liquidity Based on Intermediary Capital," Journal of the European Economic Association P\&P, pp. 456466 .

Hardin, James and Hilbe, Joseph (2003). Generalized Estimating Equations, London: Chapman and Hall

He, Z. and A. Krishnamurthy (2013) "Intermediary Asset Pricing," American Economic Review 103(2), pp. 1-43.

Holmström B. and J. Tirole (1997) "Financial Intermediation, Loanable Funds, and the Real Sector," Quarterly Journal of Economics 112(3), pp. 663-692.

Innes, R. (1990) "Limited Liability and Incentive Contracting With Ex-Ante Action Choices," Journal of Economic Theory 52, pp. 45-68.

Jensen, M. and W. Meckling (1976) "Theory of the Firm: Managerial Behavior, Agency Costs and Ownership Structure," Journal of Financial Economics 3(4), pp. 305-360.

Kim, D. and A. Santomero (1988) "Risk in banking and capital regulation," Journal of Finance 43(5), pp. 1219-1233.

Koehn, M. and A. Santomero (1980) "Regulation of bank capital and portfolio risk," Journal of Finance 35(5), pp. 1235-1244.

Merton, R. (1969) "Lifetime Portfolio Selection under Uncertainty: The Continuous-Time Case" Review of Economics and Statistics 51, 247-257.

Merton, R. (1974) "On the Pricing of Corporate Debt: The Risk Structure of Interest Rates," Journal of Finance 29(2), pp. 449-470.

Modigliani, F. and M. Miller (1958) "The Cost of Capital, Corporation Finance and the Theory of Investment," American Economic Review 48(3), pp. 261-297. 
Myers, S. and N. Majluf (1984) "Corporate Financing and Investment Decisions when Firms have Information that Investors do not have," Journal of Financial Economics 13(2), pp. 187-221.

Nuño, Galo and Carlos Thomas (2012) "Bank Leverage Cycles" Bank of Spain working paper 1222 , http://papers.ssrn.com/sol3/papers.cfm?abstract_id=2084115

Oehmke, M. (2008) "Liquidating Illiquid Collateral," working paper, Columbia University.

Oehmke, M. (2009) "Gradual Arbitrage," working paper, Columbia University.

Plantin, G. and J.-C. Rochet (2006) When Insurers Go Bust: An Economic Analysis of the Role and Design of Prudential Regulation, Princeton University Press, Princeton.

Rochet, J.-C. (1992) "Capital Requirements and the Behavior of Commercial Banks," European Economic Review 36(5), pp. 1137-1178.

Shin, H. S. (2010) Risk and Liquidity, Clarendon Lectures in Finance, Oxford University Press, Oxford.

Shleifer, A., and R. Vishny (1992) "Liquidation Values and Debt Capacity: A Market Equilibrium Approach," Journal of Finance 47(4), pp. 1343-66.

Shleifer, A., and R. Vishny (1997) "The Limits of Arbitrage," Journal of Finance 52(1), pp. 35-55.

Xiong, W. (2001) "Convergence Trading with Wealth Effects: An Amplification Mechanism in Financial Markets" Journal of Financial Economics 62, 247-292. 